\title{
Results of Parks operation for faecal incontinence after anal sphincter injury
}

\author{
GAVIN G P BROWNING, ROGER W MOTSON
}

\begin{abstract}
Parks operation for faecal incontinence was performed on 97 patients with total loss of anorectal control due to injury. All had sustained complete division of the anal sphincters as a result of trauma, anal surgery, or obstetric tears and either were incontinent or had been given a colostomy. In all patients the divided sphincters were repaired using an overlapping technique; in 93 the repair was protected by a temporary defunctioning stoma.

There was no operative mortality. Continence was completely restored in $65(78 \%)$ and improved in a further $11(13 \%)$ of the 83 patients assessed from four to 116 months postoperatively. Minor complications which did not affect the eventual clinical outcome occurred in 23 patients. Factors associated with failure of the operation included breakdown of the repair in the early postoperative period, fistula, and pelvic floor neuropathy. The results show that even after severe injury to the sphincters surgical reconstruction can restore continence in most patients.
\end{abstract}

The late Sir Alan Parks had completed this review of his anal sphincter muscle repairs and the results were presented to the British Society of Gastroenterology in September 1982 (Browning GGP, Parks AG. "Gut" 1982;23:A901-2). All the operations were

St Mark's Hospital, London EC1V 2PS

GAVIN G P BROWNING, MB, FRCSED, research fellow

The London Hospital, London E1 $1 \mathrm{BB}$

ROGER W MOTSON, MS, FRCS, senior surgical registrar

Correspondence to: Mr G G P Browning. performed by him. We gratefully acknowledge the permission of Lady Parks and the consultant surgeons at St Mark's Hospital to continue with this work after his untimely death and to publish this paper.

\section{Introduction}

Faecal incontinence may be due either to neurological disease or to injury to the anal sphincters. Injury, resulting in complete division of the anal musculature, occurs as a result of trauma, surgical mishap, or obstetric tears extending into the anal canal. Although some patients, particularly those affected by major trauma, are given a colostomy, many with operative or obstetric sphincter damage are essentially untreated. In these patients the sphincter deficiency is frequently unrecognised and may lead to years of distressing faecal incontinence and social alienation. Patients may not seek medical advice, even from their own family doctor, as they are often too ashamed and embarrassed to discuss their symptoms. Moreover, both the patient and her medical advisers may be unaware that effective treatment is possible. In 1961 a technique of direct repair of divided anal sphincters was developed which produced encouraging functional results. ${ }^{1}$ We report the results in a consecutive series of 97 patients treated between 1961 and 1982 .

\section{Method}

OPERATIVE TECHNIQUE

The operation is performed under general anaesthesia. A temporary defunctioning colostomy ${ }^{2}$ is carried out if not already present. Through a circumanal incision scarred skin is excised exposing ischiorectal fat and fibrous tissue deep in the base of the wound. When this is excised the sphincter muscle ends are exposed (fig 1). After separation of the anal skin and epithelium from the inner aspect of the sphincter the anal mucosal tube is repaired with chromic catgut (fig 2). The outer surface 

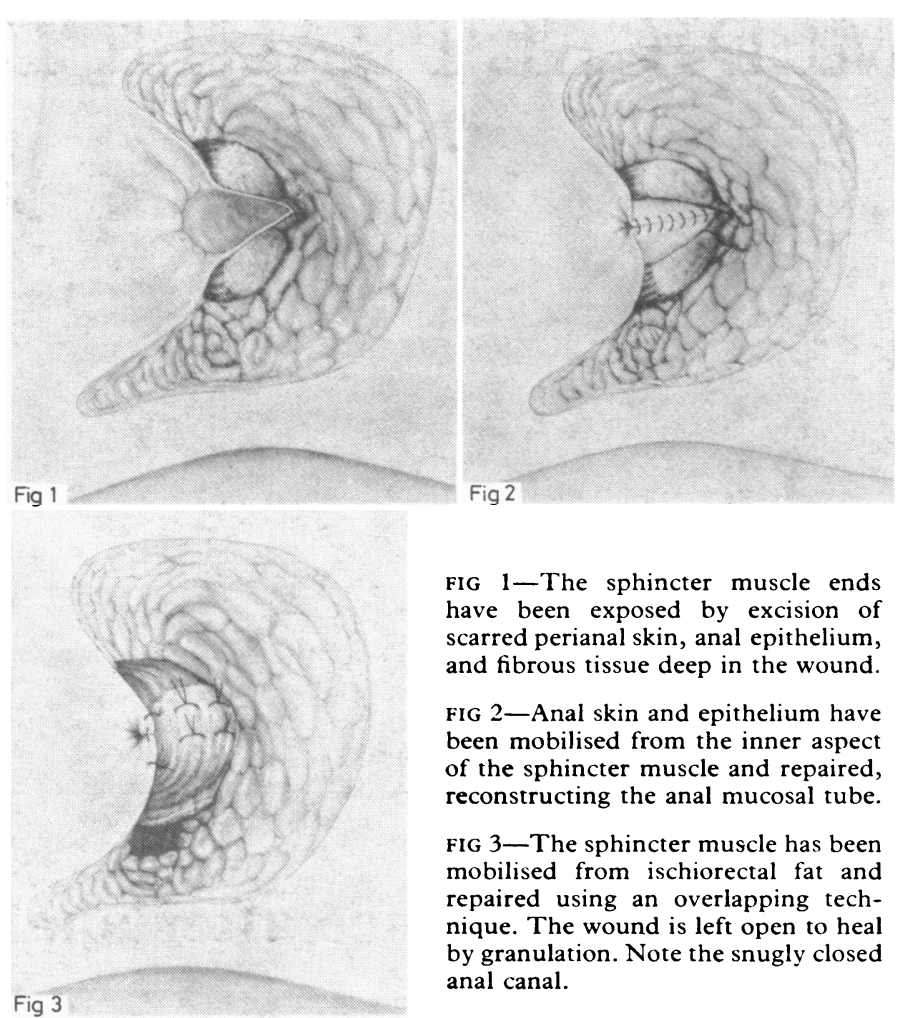

of the sphincter muscle is then carefully mobilised from ischiorectal fat. Mobilisation must be sufficient for a repair without tension but at the same time it must preserve the blood and nerve supply to the muscle. A nerve stimulator is helpful at this stage in identifying the muscle and its nerve supply. The ends of the external sphincter, and in the case of posterolateral divisions the puborectalis, are now overlapped and repaired using horizontal mattress sutures of monofilament stainless steel wire or polyglycolic acid (fig 3). The free edge of the anal mucosa is sutured to the lower edge of the muscle repair with catgut and the wound left open to heal by granulation. Healing is usually complete in six to eight weeks and the colostomy closed in two to three months.

\section{Patients}

Sphincter repair, as described above, was performed in 97 patients, 57 women and 40 men, aged 4-74 years (mean 38 years). All had faecal incontinence or a colostomy after complete division of the anal sphincters.

\section{AGE AT INJURY}

Table I shows the ages of the patients at the time of injury. Fifty eight $\left(60^{\circ} ; 35\right.$ women, 23 men) patients had sustained sphincter damage at the time of an anal operation. Injury most commonly followed fistula surgery ( 52 patients; 33 women, 19 men), anal dilatation (four patients; one woman, three men), and local excision of anal carcinoma (two patients; one woman, one man). Sphincter damage was the result of trauma in $26\left(27^{\circ}\right.$; nine women, $\left.17 \mathrm{men}\right)$ patients, a

TABLE I-Age at time of anal sphincter muscle injury and interval to repair. (All values are means (standard error of mean))

\begin{tabular}{|c|c|c|c|c|c|}
\hline & \multicolumn{2}{|c|}{$\begin{array}{l}\text { Operative injury } \\
(\mathrm{n}=58)\end{array}$} & \multicolumn{2}{|c|}{$\begin{array}{l}\text { Trauma } \\
(\mathrm{n}=26)\end{array}$} & \multirow{2}{*}{$\begin{array}{c}\text { Obstetric } \\
\text { injury } \\
(n=13)\end{array}$} \\
\hline & $\begin{array}{c}\text { Women } \\
(35)\end{array}$ & $\begin{array}{l}\text { Men } \\
(23)\end{array}$ & $\begin{array}{l}\text { Women } \\
(9)\end{array}$ & $\begin{array}{l}\text { Men } \\
(17)\end{array}$ & \\
\hline $\begin{array}{l}\text { Age (years) at injury } \\
\text { Interval (years) to repair }\end{array}$ & $\begin{array}{l}36(3) \\
10(2)\end{array}$ & $\begin{aligned} 41(4) \\
4(2)\end{aligned}$ & $\begin{aligned} & 12(2) \\
& 2(0 \cdot 6)\end{aligned}$ & $\begin{array}{r}30(3) \\
5(2)\end{array}$ & $\begin{array}{l}32(2) \\
16(3)\end{array}$ \\
\hline
\end{tabular}

major road accident in 17 (nine women, eight men) and a fall on the perineum in nine (all men). In the remaining $13\left(13^{\prime}{ }_{n}\right)$ patients sphincter damage occurred during childbirth.

Sixty four $\left(66^{\circ}{ }_{1} ; 46\right.$ women, 18 men $)$ patients were initially managed without a colostomy and were therefore incontinent. This occurred most frequently after operative or obstetric injury to the sphincter. Thirty three $\left(34^{\circ}{ }^{\prime} ; 11\right.$ women, 22 men) patients were treated initially with a defunctioning colostomy; most of these (21 patients) were in the trauma group and included eight of the nine women in this group. None of the 24 previously attempted primary or secondary sphincter repairs had been successful.

\section{SYMPTOMS AND SIGNS}

Table II shows the symptoms and signs of sphincter damage. Faecal incontinence was more common in women and was also of longer duration (mean : (SEM); women $11 \cdot 1+(1.5)$ years, men $7+(1)$ years) $\left(p<0.05, \chi^{2}\right.$ test) owing to considerable delay in presentation (table I). Diagnostic physical signs were the presence of perianal scarring, a gaping anal canal, and a palpable defect in the sphincter muscle ring; one or more of these signs was present in all 97 patients. Sphincter function was assessed physiologically in most patients.

TABLE II-Symptoms and signs in 97 patients with anal sphincter muscle division

\begin{tabular}{|c|c|c|}
\hline & $\begin{array}{c}\text { No of women } \\
(n=57)\end{array}$ & $\begin{array}{l}\text { No of men } \\
(n=40)\end{array}$ \\
\hline & \multicolumn{2}{|c|}{ Symptoms } \\
\hline Pat 1 ents without colostomy $(n=64)$ : & 46 & 18 \\
\hline Faecal incontinence & 46 & 18 \\
\hline Mucus discharge & 27 & 7 \\
\hline Patients with colostomy $(n=33)$ : & 11 & 22 \\
\hline Mucus discharge & 8 & 13 \\
\hline Gaping anal canal & & 37 \\
\hline Perianal scar & 44 & 32 \\
\hline Fistula & 11 & 3 \\
\hline Palpable sphincter defect & 51 & 32 \\
\hline
\end{tabular}

Details of the sphincter damage were determined from the clinical, physiological, and operative findings. In 51 (53\%; 38 women, 13 men) patients the injury was confined to the anterior quadrant with division of the external sphincter only. The remaining 46 (47\%; 19 women, 27 men) patients with injury laterally or posteriorly had division of both the external sphincter and puborectalis; simple division of both muscles had occurred in 37 (13 women, 24 men), and in nine (six women, three men) total disruption of the entire sphincter complex had followed major pelvic trauma.

\section{SURGICAL REPAIR}

Overlapping sphincter muscle repairs, either with stainless steel wire or more recently polyglycolic acid, were carried out in all 97 patients. A defunctioning colostomy or ileostomy was present at the time of repair in 93 patients; four refused a stoma and two of these were managed with an elemental diet.

\section{Results}

Table III shows the functional results. Continence was assessed in 83 patients four to 116 months (mean 39.2 months) after colostomy closure (four patients were repaired without a stoma). Sixty five $\left(78^{\prime \prime}\right)$ patients were completely continent of solid and liquid stool. Partial success was achieved in a further $11\left(13^{\prime \prime}\right)$ patients who could control solid but not liquid stool. The repair failed in the remaining seven $(9 \%)$ patients.

Minor complications which did not affect the eventual clinical outcome included fistula (5), stricture (16), sinus (16), and delayed healing (9); some patients had more than one complication. Factors contributing to failure of the repair included muscle necrosis (1), mechanical breakdown (2-both refused a temporary colostomy at the time of repair), fistula (1), and pelvic floor neuropathy (2). In one patient no obvious cause was found and she underwent a successful second repair two years later. 
TABLE III-Functional results after anal sphincter muscle repair in 97 patients

\begin{tabular}{|c|c|c|c|}
\hline \multirow[b]{2}{*}{ Results } & \multicolumn{3}{|c|}{ No of patients } \\
\hline & $\begin{array}{c}\text { Operative } \\
\text { injury } \\
(n=58)\end{array}$ & $\begin{array}{l}\text { Trauma } \\
(n=26)\end{array}$ & $\begin{array}{c}\text { Obstetric } \\
\text { injury } \\
(n=13)\end{array}$ \\
\hline $\begin{array}{l}\text { Continent of solid and liquid stool } \\
\text { Continent of solid stool only }\end{array}$ & 29 & 25 & 11 \\
\hline $\begin{array}{l}\text { Incontinent of all stool or permanent colostomy } \\
\text { Not assessed* }\end{array}$ & $\begin{array}{r}4 \\
14\end{array}$ & 1 & 2 \\
\hline
\end{tabular}

*One woman died of a stroke seven months after repair before closure of colostomy, eight (five women, three men) await closure, and five (three women, two men) are lost to follow up.

\section{Discussion}

Previous methods of restoring continence after sphincter division have included the use of striated muscle of skeletal origin to construct a new sphincter mechanism and attempts to repair the divided sphincter by end to end suture. ${ }^{3-10}$ Both these approaches have major disadvantages. In the former the muscle used, unlike striated muscle from the pelvic floor, is inactive at rest. "Continence depends, therefore, on consciously maintaining contraction in the new sphincter, which is difficult for prolonged periods and impossible during sleep. In repair by end to end suture the inherent tone of the external sphincter ${ }^{12}$ tends to cause retraction of the muscle ends and disruption of the repair. The present method is designed to overcome both these problems. By using muscle of pelvic floor origin automatic control of continence is achieved. In addition, the overlapping technique provides a larger area for healing between the muscle ends and allows a degree of retraction to occur without total disruption of the reconstituted sphincter ring.

It is interesting that the best results were obtained in young patients with traumatic sphincter injury. The most likely explanation is that despite severe degrees of trauma in some of these patients the remaining external sphincter muscle was healthy and functioned normally. In addition, there was relatively little delay before presentation for repair. Obstetric injury to the sphincter is usually well treated by gynaecologists, and the patients in this series represent the minority in whom primary repair fails. These patients may, however, be helped considerably by a further definitive repair. The most difficult group to treat was the operative injury group. It is likely that this was related mainly to the high incidence of previous anal operations $\left(35,60^{\circ} \%\right.$ of the 58 patients in this group had had two or more previous anal operations) and delay in presentation. Sphincter injury occurred most frequently during surgery for fistula and the results suggest that even greater care is required in assessing and treating this condition, particularly when associated with acute abscess.

The U shaped puborectalis muscle, slung around the anorectal junction above the external sphincter, occupies the lateral and posterior quadrants of the sphincter muscle ring. In rontrast, the external sphincter is circumferential and is therefore the only component of the striated sphincter musculature in the anterior quadrant. It is interesting that about half of all the injuries occurred at this site with the remainder situated in the lateral or posterior quadrants. Furthermore, anterior injury was three times more frequent in women than men, a finding which has been noted previously. ${ }^{9}$ Thus the anterior quadrant of the sphincter muscle ring seems to be particularly vulnerable to injury, especially in women, and the posterolateral quadrants more susceptible than previously thought.

There was considerable delay in presentation for repair in women in the operative and obstetric groups and this may have influenced the clinical results. Hopefully, greater awareness of the entity of anal sphincter injury as a cause of faecal incontinence and of the results which can be obtained by surgical repair will encourage patients to seek medical advice earlier.

Patients with faecal incontinence are in a continuous state of great physical and psychological hardship. ${ }^{13}$ Fear of unheralded and uncontrolled faecal soiling leads to social isolation at work, in society, and even in the family. These patients are sometimes reduced to a pathetic state by the time they finally present for treatment and they may require intensive social rehabilitation. It seems that there is a lack of awareness regarding the management of this condition, which often leads to considerable delay in treatment. In this series the longest period of continuous faecal incontinence was 35 years. The results show that no matter how severe the injury to the sphincter surgical reconstruction can completely restore continence in most patients and improve all but a few.

GGPB was supported by the Westminster Foundation and the St Mark's Research Foundation. Figures 1-3 are reproduced by kind permission of Butterworths, London.

\section{References}

1 Parks AG, McPartlin JF. Late repair of injuries of the anal sphincter. Proc $R$ Soc Med 1971;64:1187-9.

2 Browning GGP, Parks AG. A method and the results of loop colostomy. Dis Colon Rectum 1983;26:223-6.

${ }^{3}$ Chetwood $\mathrm{CH}$. Plastic operation for restoration of the sphincter ani, with report of a case. Indian Medical Record 1902;23:70-1.

${ }^{4}$ Ingelman-Sundberg A. Plastic repair of extensive defects of the anal sphincter. Acta Chir Scand 1951;101:155-7.

${ }^{5}$ Pickrell KL, Broadbent TR, Masters FW, et al. Construction of a rectal sphincter and restoration of anal continence by transplanting the gracilis muscle. Ann Surg 1952;135:853-62.

${ }^{6}$ von Rapport E. Plasticher ersatz des musculus sphincter ani. Zentralbl Chir 1952;77:579-81.

' State D, Katz A. The use of superficial transverse perineal muscles in the treatment of post surgical anal incontinence. Ann Surg 1955;142: 262-5.

${ }^{8}$ Wreden RR. A method of reconstructing a voluntary sphincter ani. Arch Surg 1929;18:841-4.

9 Blaisdell PC. Repair of the incontinent sphincter ani. Surg Gynecol Obstet 1940;70:692-7.

10 Turrell R, Gordon JB, Davis K. Plastic repair for post operative anal incontinence. Am $\mathcal{F}$ Surg 1948;76:89-91.

1 Parks AG, Porter NH, Melzak J. Experimental study of the reflex mechanism controlling the muscles of the pelvic floor. Dis Colon Rectum $1962 ; 5: 407-14$

1: Floyd WF, Walls EW. Electromyography of the sphincter ani externus in man. F Physiol 1959;122:599-609.

${ }^{13}$ Orbach CE, Bard M, Sutherland AM. Fears and defensive adaptations to the loss of anal sphincter control. Psychoanal Rev 1957;44:121-6.

(Accepted 7 April 1983)

\section{Clinical suggestion: reflective brassards for the disabled}

I am 61.1 years old and a registered disabled person, but I am not as unfortunate as many. I have arthritis of both knees: the left due to tearing the medial meniscus while cleaning my car in 1961 and the right similarly while cleaning out a smokeless fuel heater the next year. By 1975 my knees began to give me pain, and now I dare not rotate the left foot externally. I can manage with a stout walking stick, and I have an orange disc, which is of great help to me. During the week leading up to last Christmas, on separate occasions I managed to catch hold of two elderly disabled ladies who had been "bumped" by some persons in the crowds while shopping in Chorley. Fortunately, neither was seriously injured, but both suffered from shock. On other occasions I have been pushed to the ground accidentally. I would like to suggest that people who are disabled but who can walk be invited to wear a brassard, one on each arm, preferably orange and reflective, and bearing the disabled person's logo front and rear. These could be about $11 \mathrm{~cm}$ deep and easily fastened by means of Velcro. I would gladly wear these and would not consider them a stigma, although some people may prefer not to wear them. The brassards would at least give warning to non-disabled people, who could then take care and avoid any accidental contact. Obviously there are more disabled people who can walk than are in wheelchairs.-J G SEARLE, Lancashire PR6 $7 \mathrm{HH}$. 